\title{
A Highly Potent and Selective Histone Deacetylase 6 Inhibitor Prevents DSS-Induced Colitis in Mice
}

\author{
Ting Liu, ${ }^{\#}$ Renping Wang,, Haojie Xu, Yunlong Song,* and Yunpeng Qi* \\ School of Pharmacy, Second Military Medical University; No. 325 Guohe Road, Yangpu District, Shanghai 200433, \\ China.
}

Received December 28, 2016; accepted February 22, 2017; advance publication released online March 17, 2017

\begin{abstract}
Inflammatory bowel disease (IBD) is a refractory illness with remarkably increasing incidence rate all over the world. However, no desirable treatment scheme is available. Therefore, research and development of new drugs for treating IBD are urgently needed. Histone deacetylase 6 (HDAC6) is considered to be a proinflammatory factor, thus the inhibitors specifically-targeting HDAC6 may find their way in IBD treatment. In this study, we evaluated the anti-inflammatory activity of a novel potent and selective HDAC6 inhibitor, LTB2, in dextran sulfate sodium (DSS)-induced colitis mouse model. It was found that LTB2 treatment significantly alleviated DSS-induced colitis in mice, as evidenced by body weight, colon length, histological examination, and the disease activity index (DAI) scores of rectal bleeding and diarrhea. More importantly, it showed a better protective effect on the DSS-induced colitis mice than the commonly used mesalazine in the clinic. Our results demonstrated that selective HDAC6 inhibitors may have a good prospect for IBD treatment.
\end{abstract}

Key words histone deacetylase 6 inhibitor; colitis; inflammatory bowel disease; anti-inflammatory activity

Crohn's disease (CD) and ulcerative colitis (UC) are the two phenotypes of inflammatory bowel disease (IBD), of which the exact pathogenesis is still unclear. ${ }^{1)}$ The commonly used medications for IBD treatment mainly contain anti-inflammatory drugs, corticosteroids, biologics and immunosuppressants. Unfortunately, most of these medicines can only attenuate the IBD symptoms, rather than completely cure the disease, and the concomitant adverse effects of these drugs also cannot be overlooked. ${ }^{2-5)}$ With the increasing incidence rate and prevalence of IBD in most of the global areas, development of new effective and safe drugs is in great need. ${ }^{6-10)}$

Recently, histone deacetylases (HDACs) are reported to have a close link to intestinal inflammation. ${ }^{11)}$ HDACs contain 18 isoforms which are divided into four groups: class I (HDAC1, 2, 3, 8), class II (IIa, HDAC4, 5, 7, 9; IIb, HDAC6, 10), class III (SIRT1-7) and class IV (HDAC11). ${ }^{12)}$ At present, some broad-spectrum HDAC inhibitors like vorinostat (SAHA) have proved their anti-inflammatory activities in dextran sulfate sodium (DSS)-induced colitis mouse model. ${ }^{13,14)}$ However, adverse effects of these nonselective HDACi have been reported, mainly including diarrhoea, nausea, vomiting and other intestinal symptoms, which undoubtedly limit the application of HDACi in IBD treatment. ${ }^{1)}$ In fact, different HDACs may have various functions in IBD. For instance, HDAC2, 6, 9 are regarded as pro-inflammatory factors; while HDAC3 is the opposite, which is not expected to be inhibited in anti-IBD therapy. ${ }^{15-21)}$ Furthermore, global deletion of HDAC1, HDAC3 or HDAC8 is associated to embryonic lethality. $^{22-24)}$ Hence, nonselective inhibition of HDACs may not be a good strategy for treating IBD according to these results.

HDAC6 is a unique isoform involving in various diseases including neurodegeneration, tumors and inflammation. ${ }^{25}$ HDAC6 inhibitors have been tested to be effective in several inflammatory models of mice. ${ }^{26-28)}$ However, there are only a

\footnotetext{
${ }^{\#}$ These authors contributed equally to this work.

few researches about the selective HDAC6 inhibitors applied to IBD. ${ }^{18,29)}$ Tubacin (the first selective HDAC6 inhibitor) was validated to protect mice from DSS-induced colitis through promoting the inhibitory activity of Foxp $3^{+}$T-regulatory cells (Tregs) via HDAC6 suppression in 2011. ${ }^{18)}$ Although the poor pharmacokinetics of tubacin hindered its clinical development, the investigation did inspire us to exploit new selective HDAC6 inhibitors, with the hope of providing a new candidate drug for the treatment of IBD.

In previous medicinal chemistry work, we have designed and synthesized a series of novel potent HDAC6 inhibitors, which led to the discovery of LTB2 (the chemical structrue will be disclosed later). LTB2 is a highly potent and selective HDAC6 inhibitor with an $\mathrm{IC}_{50}$ value of $3.9 \mathrm{~nm}$, which is slightly better than the widely studied HDAC6 inhibitor tubastatin A. Here, we evaluated its therapeutic potential in DSS-induced colitis mice.

\section{MATERIALS AND METHODS}

Drugs and Chemicals Mesalazine (ME) was purchased from Energy Chemical of China. Tubastatin A (TA), a known selective HDAC6 inhibitor, was synthesized in our lab using the method of Butler et al. ${ }^{30)} \mathrm{ME}$ and TA were used as positive control drugs. LTB2 was designed and synthesized in our lab. The purity of TA and LTB2 is over $95 \%$ as quantitated by HPLC and their structural identity was confirmed by MS and ${ }^{1}$ H-NMR. DSS (MW=36000-50000) was purchased from MP Biomedicals (Solon, OH, U.S.A.).

Mice and Treatments All animal experimental protocols in this investigation were approved by the Administrative Committee of Experimental Animal Care and Use of the Second Military Medical University (SMMU), and consensus with National Institute of Health guidelines on the ethical use of animals. Six to eight week-old male C57BL/6J mice were obtained from Slac Laboratory Animal Co., Ltd. (Shanghai, 
China) and raised in a house maintaining relatively constant temperature at $25 \pm 1^{\circ} \mathrm{C}$ and $55 \pm 5 \%$ humidity with a light/ dark cycle of $12 \mathrm{~h}$. All mice were accommodated for one week before the experiment. When the experiment came to the end, mice were sacrificed.

DSS-Induced Colitis DSS added to the drinking water $(3 \%, w / v)$ was used to induce colitis. All mice were randomly divided into 5 groups (5 mice/group) with standard diet freely available for $7 \mathrm{~d}$ : 1) control group (water): free to drinking water; 2) colitis group (DSS): given 3\% DSS in drinking water; 3) ME group (DSS+ME): given 3\% DSS in drinking water and treated with $\mathrm{ME}(100 \mathrm{mg} / \mathrm{kg}$, intragastrically (i.g.), quaque die (q.d.)); 4) TA group (DSS+TA): given 3\% DSS in drinking water and treated with TA $(10 \mathrm{mg} / \mathrm{kg}$, intraperitoneally (i.p.), q.d.); 5) LTB2 group (DSS+LTB2): given 3\% DSS

Table 1. The Scheme of Anti-colitis Experiments in Vivo

\begin{tabular}{|c|c|c|c|c|c|}
\hline \multirow{2}{*}{ Cage } & \multirow{2}{*}{ Group } & \multirow{2}{*}{$\begin{array}{l}\text { Quantity } \\
\text { of mice }\end{array}$} & \multicolumn{3}{|c|}{ Administration } \\
\hline & & & Dose (mg/kg) & Schedule & Route \\
\hline 1 & Water & 5 & 0 & $\operatorname{cont}^{c)} \times 7$ & p.o. \\
\hline 2 & $\operatorname{DSS}^{a)}$ & 5 & $3 \%{ }^{b)}$ & $\operatorname{cont}^{c)} \times 7$ & p.o. \\
\hline 3 & $\mathrm{DSS}+\mathrm{ME}$ & 5 & $3 \%+100$ & q.d. $\times 7$ & i.g. \\
\hline 4 & $\mathrm{DSS}+\mathrm{TA}$ & 5 & $3 \%+10$ & q.d. $\times 7$ & i.p. \\
\hline 5 & $\mathrm{DSS}+\mathrm{LTB} 2$ & 5 & $3 \%+10$ & q.d. $\times 7$ & i.p. \\
\hline
\end{tabular}

a) Dextran sodium sulfate, dissolved in water. $b$ ) Weight of DSS/volume of water. c) Drink continuously during experiments. 1 . Water: the mice were given drinking water only; 2 . DSS: colitis group, the mice were given 3\% DSS in drinking water; 3 . DSS +ME: the mice were given 3\% DSS in drinking water and were treated with ME $(100 \mathrm{mg} / \mathrm{kg}) ; 4$. DSS + TA: the mice were given $3 \%$ DSS in drinking water and were treated with TA $(10 \mathrm{mg} / \mathrm{kg}) ; 5$. DSS + LTB2: the mice were given $3 \%$ DSS in drinking water and were treated with LTB2 $(10 \mathrm{mg} / \mathrm{kg})$. in drinking water and treated with LTB2 $(10 \mathrm{mg} / \mathrm{kg}$, i.p., q.d.). The groups, dosing, and drug administration were presented in Table 1. TA and LTB2 were respectively dissolved in $15 \%$ captisol (sulfobutylether- $\beta$-cyclodextrin) aqueous solution with 4\% dimethyl sulfoxide (DMSO) (Sigma-Aldrich, Taufkirchen, Germany). ME was suspended in $1 \%$ sodium carboxymethyl cellulose (CMC-Na) aqueous solution containing $0.5 \%$ soya oil. Body weights of the mice were recorded daily. Severity of diarrhea and rectal bleeding was assessed according to the scores ranging from 0 to $4 .^{31)}$ Diarrhea score: 0 , normal; 1, slightly loose feces; 2, loose feces; 3, semi-liquid stool; 4, liquid stool. Rectal Bleeding scores: 0, normal; 1, blood detectable on hemocult paper (Beckman Coulter, Mississauga, Canada); 2, blood visible in stool; 3 , extensive blood in stool; 4 , extensive blood in stool and blood around anus. All mice were fasted for $12 \mathrm{~h}$ before operation. Colon lengths were measured and the colon tissues were then fixed by $10 \%$ neutral buffered formalin (Weigesi. Bio Tech. Co., Ltd., Guangzhou, China) on the seventh day.

Histology The fixed colon tissues were stained with hematoxylin and eosin (H\&E) by standard operation and examined under a light microscope. All results were tackled by blinded analysis according to the morphological criteria. ${ }^{31,32)}$

Statistical Analysis Data were displayed in the format of the mean \pm standard deviation (S.D.). Statistical analysis was operated on the platform of Prism 5.0 (GraphPad Software, San Diego, CA, U.S.A.), applying two-tailed Mann-Whitney test with $95 \%$ of confidence intervals to evaluate the significance of differences among the groups where necessary. $p$-Value below 0.05 means statistically significant.

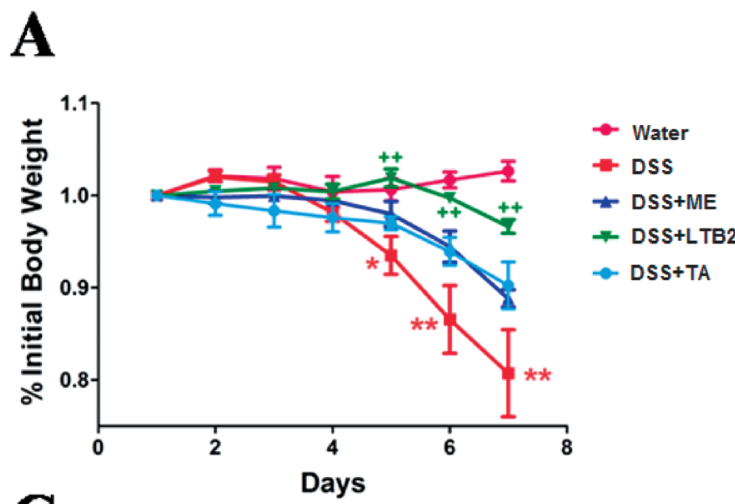

B
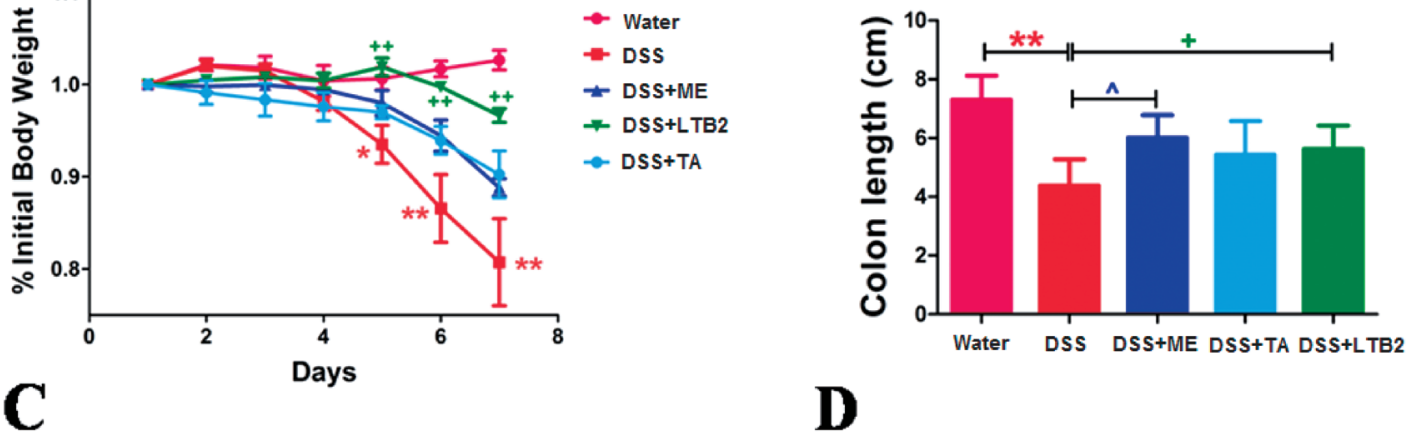

D
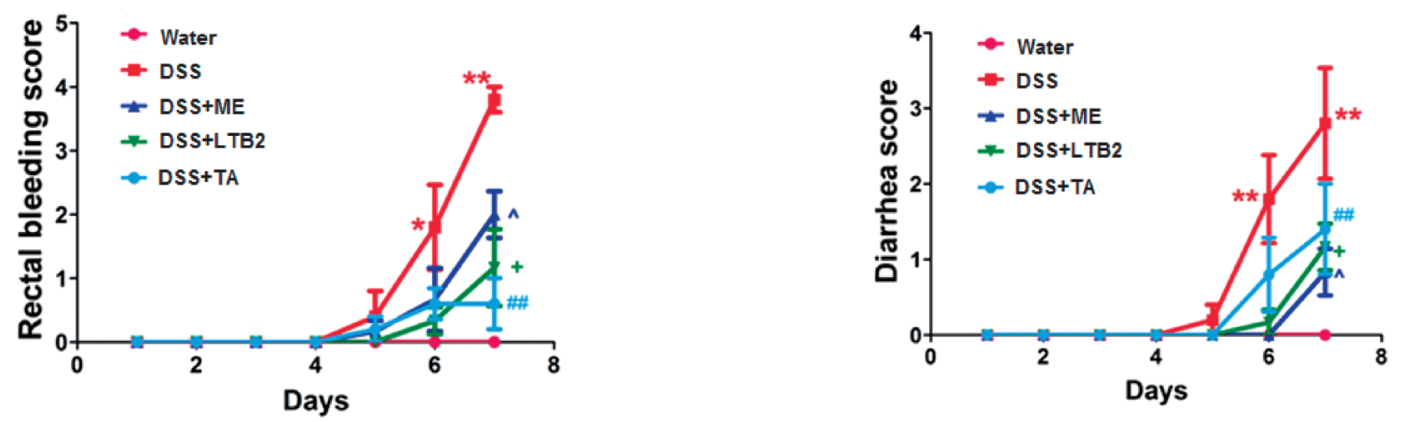

Fig. 1. Evaluation of Colitis

(A) Body weights of the mice. (B) Comparison of the colon lengths. (C) Rectal bleeding scores. (D) Diarrhea scores $\left(* * p<0.01,{ }^{*} p<0.05 ;{ }^{\wedge} p<0.05\right.$; ${ }^{++} p<0.01,{ }^{+} p<0.05$; \#\# $p<0.01$ ). 


\section{RESULTS}

LTB2 and TA Exerted Positive in Vivo Anti-inflammatory Activities as Selective HDAC6 Inhibitors The aqueous solution containing 3\% DSS has been widely applied to induce mouse colitis, which imitates human IBD, particularly similar to UC. ${ }^{31,32)}$ We tested the in vivo anti-colitis activity of LTB2 in DSS-induced mouse model, with ME and TA as positive compounds. Body weight, diarrhea and rectal bleeding of mice were recorded every day to evaluate the colitis, and results are presented in Fig. 1. The histological examination results of the colon tissue are shown in Fig. 2, which directly reflect the severity of colitis.

Body weights of the colitis mice were significantly decreased after DSS-treatment (Fig. 1A), and obvious rectal bleeding and diarrhea were examined for this group (Figs. $1 C, D)$. At the same time, the colitis mice had shorter colon length, compared with the normal control group (water group). However, compared with the colitis group, mice receiving LTB2 lost remarkably less weight on the fifth, sixth and seventh day, and they had recovered rectal bleeding, diarrhea and longer colon lengths (Fig. 1). Histological analysis (Fig. 2) further confirmed that LTB2 could protect mice from severe inflammation. The colitis mice nearly lost all of the crypts and surface epithelia (Fig. 2B), whereas the LTB2-treated colitis group had recovered crypts and surface epithelia (Fig. 2E). Taken together, our compound LTB2 showed a sound efficacy against colitis, comparable or even better than ME and TA. These data indicated that LTB2 was promising for colitis treatment.

\section{DISCUSSION}

Pro-inflammatory function of HDAC6 has been validated. HDAC6 can regulate the reactive oxygen species (ROS)-mitogen-activated protein kinase (MAPK)-nuclear factor-kappaB $(\mathrm{NF}-\kappa \mathrm{B})$ /activator protein-1 (AP-1) pathways, which leads to the expression of pro-inflammatory genes. ${ }^{17)}$ In CD8 T cell-associated skin inflammation models, HDAC6 participates T-cell receptor signaling to modulate the proliferation and activation of CD $8 \mathrm{~T}$ cells during inflammatory response. ${ }^{27)}$ Activation of HDAC6 induced by clostridium difficile toxin A causes hyperdeacetylation of tubulin and leads to depolymerization of microtubule in mouse intestine, which finally leads to severe inflammation. ${ }^{26}$ In addition, HDAC6 deficiency upregulates the acetylation level of microtubule, which results in enhanced p38 signaling and leads to the production of anti-inflammatory interleukin (IL)-10. ${ }^{33)}$ HDAC6 suppression can inhibit the release of pro-inflammatory cytokines mainly including tumor necrosis factor (TNF)- $\alpha$ and IL- $6 .^{28)}$ All these investigations
$\mathbf{A}$

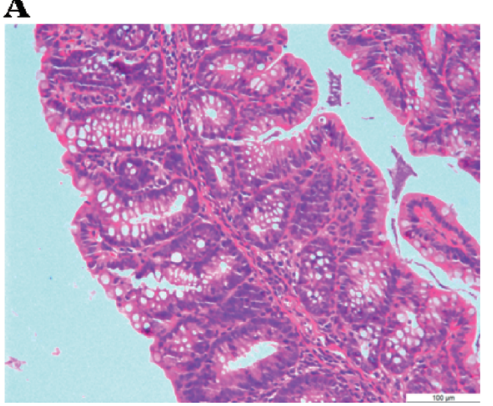

C

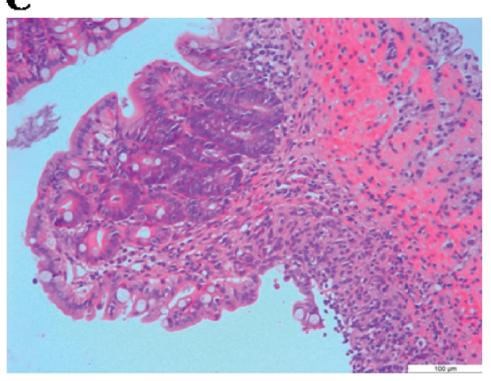

$\mathbf{E}$

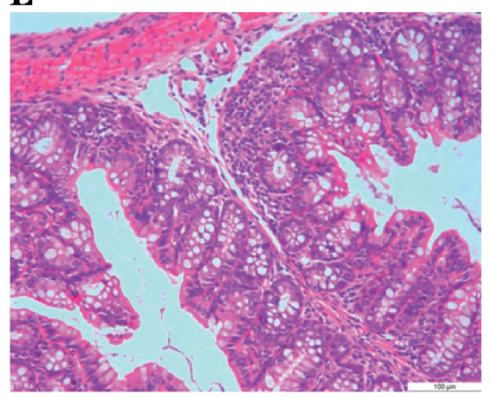

B

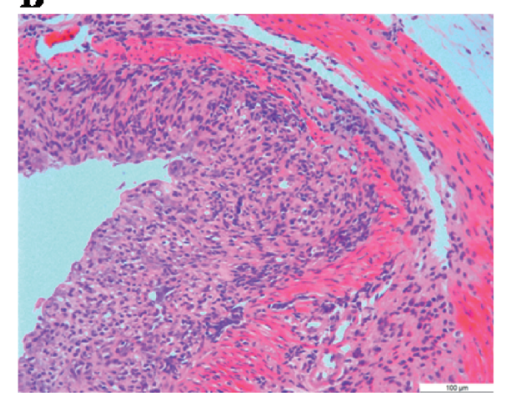

D

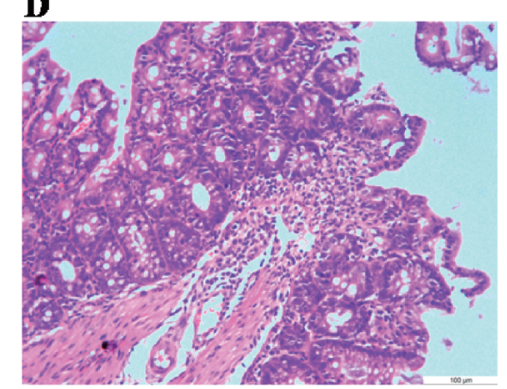

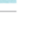

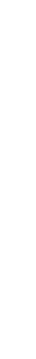

Fig. 2. A-E: The Histological Examination Results of Colon Tissues Stained by Hematoxylin and Eosin from Control (A), Colitis (B), ME-Treated Colitis (C), TA-Treated Colitis (D), and LTB2-Treated Colitis (E) Groups, Respectively 
demonstrate that HDAC6 could be a promising target for antiinflammation including IBD.

In this study, the anti-inflammatory activity of LTB2 (which was firstly designed and synthesized by our group) on DSS-induced colitis model of mice were evaluated. LTB2 was found to be efficacious at $10 \mathrm{mg} / \mathrm{kg}$ by intraperitoneal injection in C57BL/6J colitis mice. More importantly, LTB2 exhibited better efficacy than the commercial available medicine ME, and seemed to be superior to TA on suppression of colitis symptoms. The results suggest that selective HDAC6 inhibitors are indeed effective for DSS-induced colitis and our compound LTB2 is more potent than ME. More importantly, HDAC6 is considered to be dispensable for normal survival of mice. ${ }^{34)}$ A selective HDAC6 inhibitor (HPB) was reported to induce tumor shrinkage without any significant side effects observed in tumor-xenograft mice and it was well tolerated in animals even at $300 \mathrm{mg} / \mathrm{kg}$. ${ }^{35}$ ) Another selective HDAC6 inhibitor tubastatin A showed no neuronal toxicity in a neurodegeneration model. ${ }^{36)}$ Based on current data in literature, it seems that HDAC6 inhibition is not related to any serious toxicity. ${ }^{37)}$ Therefore, selective HDAC6 inhibitors may provide a safer therapeutics for IBD.

In conclusion, this study suggested that selective HDAC6 inhibitors have a promising prospect in IBD treatment. Especially, the compound LTB2 discovered by our group can protect mice from DSS-induced colitis significantly, and it might be a potential therapeutic drug candidate for this disease.

Acknowledgment Thanks for the support of National Natural Science Foundation of China 81172928.

Conflict of Interest The authors declare no conflict of interest.

\section{REFERENCES}

1) Felice C, Lewis A, Armuzzi A, Lindsay JO, Silver A. Review article: selective histone deacetylase isoforms as potential therapeutic targets in inflammatory bowel diseases. Aliment. Pharmacol. Ther., 41, 26-38 (2015).

2) Joshi R, Kumar $S$, Unnikrishnan $M$, Mukherjee $T$. Free radical scavenging reactions of sulfasalazine, 5-aminosalicylic acid and sulfapyridine: mechanistic aspects and antioxidant activity. Free Radic. Res., 39, 1163-1172 (2005).

3) Sousa P, Allez M. Complications of biologics in inflammatory bowel disease. Curr. Opin. Gastroenterol., 31, 296-302 (2015).

4) Abraham BP, Sellin JH. Disability in inflammatory bowel disease. Gastroenterol. Clin. North Am., 41, 429-441 (2012).

5) Nielsen $\mathrm{OH}$, Coskun $\mathrm{M}$, Steenholdt $\mathrm{C}$, Rogler G. The role and advances of immunomodulator therapy for inflammatory bowel disease. Expert Rev. Gastroenterol. Hepatol., 9, 177-189 (2015).

6) Ng SC, Tang W, Ching JY, Wong M, Chow CM, Hui AJ, Wong TC, Leung VK, Tsang SW, Yu HH, Li MF, Ng KK, Kamm MA, Studd C, Bell S, Leong R, de Silva HJ, Kasturiratne A, Mufeena MN, Ling KL, Ooi CJ, Tan PS, Ong D, Goh KL, Hilmi I, Pisespongsa P, Manatsathit S, Rerknimitr R, Aniwan S, Wang YF, Ouyang Q, Zeng Z, Zhu Z, Chen MH, Hu PJ, Wu K, Wang X, Simadibrata M, Abdullah M, Wu JC, Sung JJ, Chan FK, Asia-Pacific Crohn's and Colitis Epidemiologic Study (ACCESS) Study Group. Incidence and phenotype of inflammatory bowel disease based on results from the Asia-pacific Crohn's and colitis epidemiology study. Gastroenterology, 145, 158-165.e2 (2013).

7) Tursi A, Elisei W, Picchio M. Incidence and prevalence of inflam- matory bowel diseases in gastroenterology primary care setting. Eur. J. Intern. Med., 24, 852-856 (2013).

8) Thia KT, Loftus EV Jr, Sandborn WJ, Yang SK. An update on the epidemiology of inflammatory bowel disease in Asia. Am. J. Gastroenterol., 103, 3167-3182 (2008).

9) Hou JK, El-Serag H, Thirumurthi S. Distribution and manifestations of inflammatory bowel disease in Asians, Hispanics, and African Americans: a systematic review. Am. J. Gastroenterol., 104, 2100-2109 (2009).

10) Kaplan GG. The global burden of IBD: from 2015 to 2025. Nat. Rev. Gastroenterol. Hepatol., 12, 720-727 (2015).

11) Glauben R, Batra A, Stroh T, Erben U, Fedke I, Lehr HA, Leoni F, Mascagni P, Dinarello CA, Zeitz M, Siegmund B. Histone deacetylases: novel targets for prevention of colitis-associated cancer in mice. Gut, 57, 613-622 (2008).

12) de Ruijter AJ, van Gennip AH, Caron HN, Kemp S, van Kuilenburg AB. Histone deacetylases (HDACs): characterization of the classical HDAC family. Biochem. J., 370, 737-749 (2003).

13) Glauben R, Batra A, Fedke I, Zeitz M, Lehr HA, Leoni F, Mascagni P, Fantuzzi G, Dinarello CA, Siegmund B. Histone hyperacetylation is associated with amelioration of experimental colitis in mice. $J$. Immunol., 176, 5015-5022 (2006).

14) Zimmerman MA, Singh N, Martin PM, Thangaraju M, Ganapathy V, Waller JL, Shi HD, Robertson KD, Munn DH, Liu KB. Butyrate suppresses colonic inflammation through HDAC1-dependent Fas upregulation and Fas-mediated apoptosis of T cells. Am. J. Physiol. Gastrointest. Liver Physiol., 302, G1405-G1415 (2012).

15) Turgeon N, Gagne JM, Blais M, Gendron FP, Boudreau F, Asselin C. The acetylome regulators Hdacl and Hdac2 differently modulate intestinal epithelial cell dependent homeostatic responses in experimental colitis. Am. J. Physiol. Gastrointest. Liver Physiol., 306, G594-G605 (2014).

16) Turgeon N, Blais M, Gagne JM, Tardif V, Boudreau F, Perreault N, Asselin C. HDAC1 and HDAC2 restrain the intestinal inflammatory response by regulating intestinal epithelial cell differentiation. PLOS ONE, 8, e73785 (2013).

17) Youn GS, Lee KW, Choi SY, Park J. Overexpression of HDAC6 induces pro-inflammatory responses by regulating ROS-MAPK-NFkappaB/AP-1 signaling pathways in macrophages. Free Radic. Biol. Med., 97, 14-23 (2016).

18) de Zoeten EF, Wang L, Butler K, Beier UH, Akimova T, Sai H, Bradner JE, Mazitschek R, Kozikowski AP, Matthias P, Hancock WW. Histone deacetylase 6 and heat shock protein 90 control the functions of Foxp3(+) T-regulatory cells. Mol. Cell. Biol., 31, 2066-2078 (2011).

19) Beier UH, Wang LQ, Han RX, Akimova T, Liu YJ, Hancock WW. Histone deacetylases 6 and 9 and Sirtuin-1 control Foxp3(+) regulatory $\mathrm{T}$ cell function through shared and isoform-specific mechanisms. Sci. Signal., 5, ra45 (2012).

20) de Zoeten EF, Wang L, Sai H, Dillmann WH, Hancock WW. Inhibition of HDAC9 increases T regulatory cell function and prevents colitis in mice. Gastroenterology, 138, 583-594 (2010).

21) Alenghat T, Osborne LC, Saenz SA, Kobuley D, Ziegler CG, Mullican SE, Choi I, Grunberg S, Sinha R, Wynosky-Dolfi M, Snyder A, Giacomin PR, Joyce KL, Hoang TB, Bewtra M, Brodsky IE, Sonnenberg GF, Bushman FD, Won KJ, Lazar MA, Artis D. Histone deacetylase 3 coordinates commensal-bacteria-dependent intestinal homeostasis. Nature, 504, 153-157 (2013).

22) Lagger G, O'Carroll D, Rembold M, Khier H, Tischler J, Weitzer G, Schuettengruber B, Hauser C, Brunmeir R, Jenuwein T, Seiser C. Essential function of histone deacetylase 1 in proliferation control and CDK inhibitor repression. EMBO J., 21, 2672-2681 (2002).

23) Haberland M, Mokalled MH, Montgomery RL, Olson EN. Epigenetic control of skull morphogenesis by histone deacetylase 8. Genes Dev., 23, 1625-1630 (2009).

24) Bhaskara S, Chyla BJ, Amann JM, Knutson SK, Cortez D, Sun ZW, 
Hiebert SW. Deletion of histone deacetylase 3 reveals critical roles in $\mathrm{S}$ phase progression and DNA damage control. Mol. Cell, 30, 61-72 (2008).

25) Seidel $C$, Schnekenburger $M$, Dicato $M$, Diederich M. Histone deacetylase 6 in health and disease. Epigenomics, 7, 103-118 (2015).

26) Nam HJ, Kang JK, Kim SK, Ahn KJ, Seok H, Park SJ, Chang JS, Pothoulakis C, Lamont JT, Kim H. Clostridium difficile toxin A decreases acetylation of tubulin, leading to microtubule depolymerization through activation of histone deacetylase 6 , and this mediates acute inflammation. J. Biol. Chem., 285, 32888-32896 (2010).

27) Tsuji G, Okiyama N, Villarroel VA, Katz SI. Histone deacetylase 6 inhibition impairs effector CD8 T-cell functions during skin inflammation. J. Allergy Clin. Immunol., 135, 1228-1239 (2015).

28) Vishwakarma S, Iyer LR, Muley M, Singh PK, Shastry A, Saxena A, Kulathingal J, Vijaykanth G, Raghul J, Rajesh N, Rathinasamy S, Kachhadia V, Kilambi N, Rajgopal S, Balasubramanian G, Narayanan S. Tubastatin, a selective histone deacetylase 6 inhibitor shows anti-inflammatory and anti-rheumatic effects. Int. Immunopharmacol., 16, 72-78 (2013).

29) Do A, Reid RC, Lohman RJ, Sweet MJ, Fairlie DP, Iyer A. An HDAC6 inhibitor confers protection and selectively inhibits B-cell infiltration in DSS-induced colitis in mice. J. Pharmacol. Exp. Ther., 360, 140-151 (2016)

30) Butler KV, Kalin J, Brochier C, Vistoli G, Langley B, Kozikowski AP. Rational design and simple chemistry yield a superior, neuroprotective HDAC6 inhibitor, tubastatin A supporting information. $J$. Am. Chem. Soc., 132, 10842-10846 (2010).
31) Cooper HS, Murthy SN, Shah RS, Sedergran DJ. Clinicopathologic study of dextran sulfate sodium experimental murine colitis. Lab. Invest., 69, 238-249 (1993).

32) Okayasu I, Hatakeyama S, Yamada M, Ohkusa T, Inagaki Y, Nakaya R. A novel method in the induction of reliable experimental acute and chronic ulcerative colitis in mice. Gastroenterology, 98, 694-702 (1990).

33) Wang B, Rao YH, Inoue $M$, Hao R, Lai CH, Chen D, McDonald SL, Choi MC, Wang Q, Shinohara ML, Yao TP. Microtubule acetylation amplifies p38 kinase signalling and anti-inflammatory IL-10 production. Nat. Commun., 5, 3479 (2014).

34) Zhang Y, Kwon S, Yamaguchi T, Cubizolles F, Rousseaux S, Kneissel M, Cao C, Li N, Cheng HL, Chua K, Lombard D, Mizeracki A, Matthias G, Alt FW, Khochbin S, Matthias P. Mice lacking histone deacetylase 6 have hyperacetylated tubulin but are viable and develop normally. Mol. Cell. Biol., 28, 1688-1701 (2008).

35) Lee J-H, Ngo L, Venta-Perez G, Choy ML, Marks PA, Yao Y, Mahendran A, Breslow R. Creation of a histone deacetylase 6 inhibitor and its biological effects. Proc. Natl. Acad. Sci. U.S.A., 112, 12005-12010 (2015).

36) Butler KV, Kalin J, Brochier C, Vistoli G, Langley B, Kozikowski AP. Rational design and simple chemistry yield a superior, neuroprotective HDAC6 inhibitor, tubastatin A. J. Am. Chem. Soc., 132, 10842-10846 (2010).

37) Witt O, Deubzer HE, Milde T, Oehme I. HDAC family: What are the cancer relevant targets? Cancer Lett., 277, 8-21 (2009). 